\title{
Televisiones y democracias: Mass Media y televisión web en la Universidad Externado de Colombia
}

Recibido: 27 de agosto de 2012

Aceptado: 07 de marzo de 2013

Publicado: 29 de noviembre de 2013
Felipe Cardona del Real

luis.cardona@uexternado.edu.co

Universidad Externado de Colombia

Resumen: El entendimiento de la democracia, como forma de organización política, ha planteado en muchos escenarios el debate de qué tan pura es cuando es representativa y qué tan efectiva cuando es "pura" o directa, además de pensarse para las polis o lugares con ubicación geográfica concreta, contrario al concepto de "ciudades globales" planteado por Saskia Sassen. Desde esta discusión se puede abordar la televisión como medio masivo del siglo XX, financiado y operado por gobiernos o empresas privadas, ejerciendo el poder simbólico en una nación, visto desde las formas de poder en las sociedades modernas de John B. Thompson y como forma organizativa que a todas luces ejemplifica a una democracia representativa desde la escogencia de temas, personajes, discurso e incluso de flujos de trabajo tecnológico.

La televisión, a partir de la web 2.0, no solo invita a esa televisión massmediática a migrar a un entorno ubicuo, flexible y poderoso (el de la computación en la nube y la movilidad) sino que invita a la audiencia a que haga parte de la producción de esta nueva televisión, en flujos de trabajo similares a los de la televisión del siglo XX, y en flujos nuevos planteados por los grandes jugadores de la Internet de la segunda década del siglo XXI. En la Universidad Externado de Colombia se ha investigado empírica y exhaustivamente la televisión migrada a Internet, asumida con un flujo de trabajo similar al de la televisión masiva del XX, pero con una intervención de actores (prosumidores-alumnos) más flexible y abierta que la de la televisión "representativa". Si a esto se le suma la llegada de los Hangouts de Google, que plantea una apertura volcada al usuario final con habilidades web y redes sociales como potencial audiencia, que a su vez también puede intervenir en la producción, el panorama de la televisión en el siglo XXI se torna no solo democrático por definición, sino "directo" en cuanto a dicha forma de organización política. 
Palabras clave: Televisión, democracia, democracia directa, representatividad, tecnología, producción en vivo, producción pregrabada, video, audiovisual, webapp, livestream, Universidad Externado de Colombia, televisión web, prosumidor.

Abstract: The understanding of democracy as a political organization form, has in many scenarios the debate on how pure is in a representative form and how effective is when is "pure" or direct democracy, as well as thought for the "polis" or places with an specific geographic location, contrary to the Saskia Sassen concept of "global cities". From this discussion, we can address the television as a twentieth century mass media, funded and operated by governments or private companies, exercising symbolic power in a nation, as seen by the John B. Thompson power forms in modern societies, and as an organizational form that clearly exemplifies a representative democracy from the choice of themes, characters, speech and even workflow technology.

The Web 2.0 TV not only allows this massmediatic TV to migrate to a ubiquitous environment, flexible and powerful (that of cloud computing and mobility) but invites the audience to be part of as a production crew of this new television, which workflow is similar to the TV of the twentieth century, and to the new workfows purposed by major Internet players in the second decade of the XXI century. In Externado University this phenomena has been investigated thorough an empirical and intense way the migrated to Internet television, with a workflow similar to the 20th century massive TV, but with the intervention of actors (prosumer-students) in a more flexible and open way than the "representative" television. In addition of this, the arrival of Google Hangouts, which advocates for an opening to the end user with web skills, and social networks as a potential audience, which may also be involved in the production, the future of the TV in this century becomes by definition not only democratic, but also "direct" about this political organization form.

Key words: Television, Democracy, Direct Democracy, Representativeness, Tecnology, Live Production, Recorded Production, Video, Audiovisual, Webapp, Livestream, Externado University of Colombia, Web TV, Prosumer.

\section{Democracia y eufemismos}

Hablar de democracia luego de siglos de planteado el concepto, exige una revisión acertada más que extensa y varios cuestionamientos necesarios. En una búsqueda rápida por fuentes indexadas para público general y en sitios académicos hoy en Internet (posibilidad existente hoy gracias a la Web 2.0) no es difícil encontrar significados de diversas fuentes sobre democracia, menciones de la antigua Grecia, como una forma de organización o sistema de gobierno que se opone a la oligarquía ("gobierno de pocos") y a la monarquía ("gobierno de uno"). En la democracia, entendida como el "gobierno de todos" o etimológicamente como el gobierno (kratos) del pueblo (demos), "cada ciudadano ejercía directamente su voluntad a través del voto en asambleas" (EducarChile, 2008). 
En el diccionario online Merriam-Webster (2013) se define en inglés Democracy como un gobierno "cuyo poder supremo reside en el pueblo y es ejercido por él directa o indirectamente, a través de un sistema de representación, involucrando usualmente elecciones libres y periódicas"1.

El ejercicio de este poder supremo puede ser por la vía directa o indirecta. Tampoco es difícil encontrar en la web ejemplos de estos dos tipos de democracia: se habla de Suecia, Estados Unidos o Islandia como ejemplos de la directa, y son casi interminables los titulares de prensa que denuncian escándalos de corrupción de los países con democracia indirecta o representativa, como en Colombia, en donde la proverbial corrupción da para titulares de todos los calibres ${ }^{2}$.

Incluso en democracias más o menos antiguas (en países con más o menos recursos) la corrupción está a la orden del día. Entonces, ¿qué "ruido" hay entre la elección de los representantes y su periodo de gobierno? ¿Acaso el "sistema de representación” y el poder que el pueblo delega en sus representantes (según el diccionario Merriam-Webster) se parece a la oligarquía, o incluso a la monarquía?

En la discusión sobre determinismos tecnológicos y sociales (Winner, 1985), Heilbroner (1967) considera que los cambios tecnológicos, que nunca son fortuitos sino consecuentes los unos con los otros, moldean la creación de una clase social de expertos necesarios para el buen uso de dichas tecnologías y, de paso, de los cambios sociales que les preceden. Una suerte de “oligarquía de ilustrados" y se pone el ejemplo del cambio social a raíz del cambio del molino manual al molino de vapor (ibídem). Este sería, tal vez, el mejor de los casos de democracia representativa (la de "los idóneos") pero los vaivenes electorales periódicos de este sistema de gobierno hacen que factores más allá de la idoneidad entren a influir en la decisión de voto.

En Islandia, a raíz del mal manejo de la economía por parte de los bancos y gobierno central, la población tomó en serio su poder y optó por un tipo de democracia directa, logrando derribar al gobierno de turno y nacionalizando la banca, entre otros logros (Democracia Directa Digital, 2011). Es un tipo de democracia que exige de su población una mayor participación. En otros portales, y a partir de muchos movimientos ciberactivistas de indignados, han surgido conceptos como el "D3" ("democracia digital directa"), "voto telemático" (Carracedo, Pérez y Carracedo, 2010) o "democracia líquida" (2012), que entran a reforzar las ideas de democracia directa que se debaten recientemente, como alternativa a una democracia representativa o indirecta y a todos sus escándalos de corrupción.

1 Texto original en inglés: "A government in which the supreme power is vested in the people and exercised by them directly or indirectly through a system of representation usually involving periodically held free elections".

2 Cabe destacar el caso "El carrusel de la contratación", del ex alcalde de Bogotá Samuel Moreno, elegido por voto popular (El Tiempo, 2012) o el del ex presidente Álvaro Uribe Vélez, quien fue el primero en gobernar por dos periodos reformando la constitución durante su primer mandato, en un escándalo llamado la "Yidis-Política" (Cronicon.net, 2011). 
Si estos debates atañen al ejercicio del poder político de cara a una sociedad, ¿esta misma discusión se podrá llevar a entornos de trabajo massmediático como el de la televisión, prensa o la radio? Si estos medios masivos en el siglo XX se dirigían a una población, desarrollaban contenido para ser socialmente aceptados, escogían temas de discurso y personajes para que calaran en los intereses de toda una sociedad, ¿tantas funciones y responsabilidades se podrían comparar a las dinámicas planteadas por los tipos de democracia ya mencionados?

Si se toma en cuenta que la operatibilidad de la televisión fue posible durante muchos años por gobiernos o empresas privadas, que cuidaban de los intereses de poblaciones o público objetivo, ¿podría hablarse de un nivel de representatividad que el medio detenta frente a un grupo social? ¿Podría hablarse también de una democracia, o de una forma de organización que eligió a personajes y discursos representativos de dichos medios? Si quedan dudas, habría que examinar la historia de la televisión durante el siglo XX y lo que lleva el siglo XXI.

\section{2. ¿Televisiones masivas, televisiones democráticas?}

Desde el siglo XIX, cuando los experimentos con selenio y las especulaciones con la fototelegrafía (cuando Paul Gottlieb Nipkow y su disco intentaban transmitir fantasmagóricas imágenes a distancia, todo a la sombra del prodigio del cine que acaparaba la atención de públicos y la energía de emprendedores) desde ese entonces la televisión, la de las imágenes a distancia teletransmitidas en tiempo real, fue pensada como un flujo de comunicación en una sola dirección: la de ida.

Pensar en flujos de video en tiempo real de ida y vuelta era digno de la ciencia ficción, deseos planteados a un público infantil en cómics como Dick Tracy. Iniciativas "inverosímiles" a un público que ve posible lo imposible.

Cuando la televisión se materializa a partir de esa primera transmisión de la $B B C$ en septiembre de 1929, gracias a John Logie Baird, la idea era clara: transmitir imágenes y sonidos a un público que se limitaría a ver y escuchar, a una población (luego llamada "masa") que en principio no tendría la capacidad de contestar el mensaje de igual manera (ni en imágenes ni en sonidos).

En cuanto al mensaje, ¿qué se debería mostrar en esta transmisión unidireccional? Las posibilidades podrían ser infinitas, lo cierto es que debería ser un contenido que tuviera que ver con esa población, que llamara su atención, y (desde una óptica de política pública) que entretuviera, educara y construyera ciudadanía.

Muchos avances siguieron a la "televisión mecánica" de Baird. Si bien su desarrollo se interrumpió por las dos guerras mundiales, la televisión electrónica dio la pauta a futuro: los alemanes demostraron innovación en las Olimpiadas de 1936, luego los norteamericanos, después los japoneses en los Juegos Olímpicos de 1962 con la primera 
transmisión satelital... Todos los gobiernos y empresas privadas que intervinieron usaron la tecnología televisiva como un bien preciado y único, con un sentido de responsabilidad, el que se tiene cuando se posee algo que nadie más tiene y que hay que compartir, distribuir o vender.

Los gobiernos y empresas, como lo expresa Winner(1985), han hecho uso de infraestructuras tecnológicas para afianzar su poder, y a largo plazo, para beneficiar a algunos sectores de la población. Tecnologías para quienes pueden pagarla o a favor de los acomodados. En el caso de la televisión, con contenidos simbólicos hegemónicos que privilegian a las clases dominantes por encima de las menos pudientes.

Toda una discusión alrededor de las consecuencias del uso tecnológico de la transmisión de audio y video en tiempo real, desde dos o más fuentes de captura (cámaras de estudio o de campo), cuyas señales llegan a un centro de producción (switcher, máster, isla de producción o unidad móvil) que las procesa y las convierte en un solo producto en vivo (transmitidas a través de un espectro electromagnético) o en diferido (grabadas en un dispositivo de almacenamiento para emitir después). El flujo de trabajo básico de televisión se puede entender mejor en la siguiente gráfica:

Figura 1: Flujo de trabajo básico de producción televisiva en vivo.

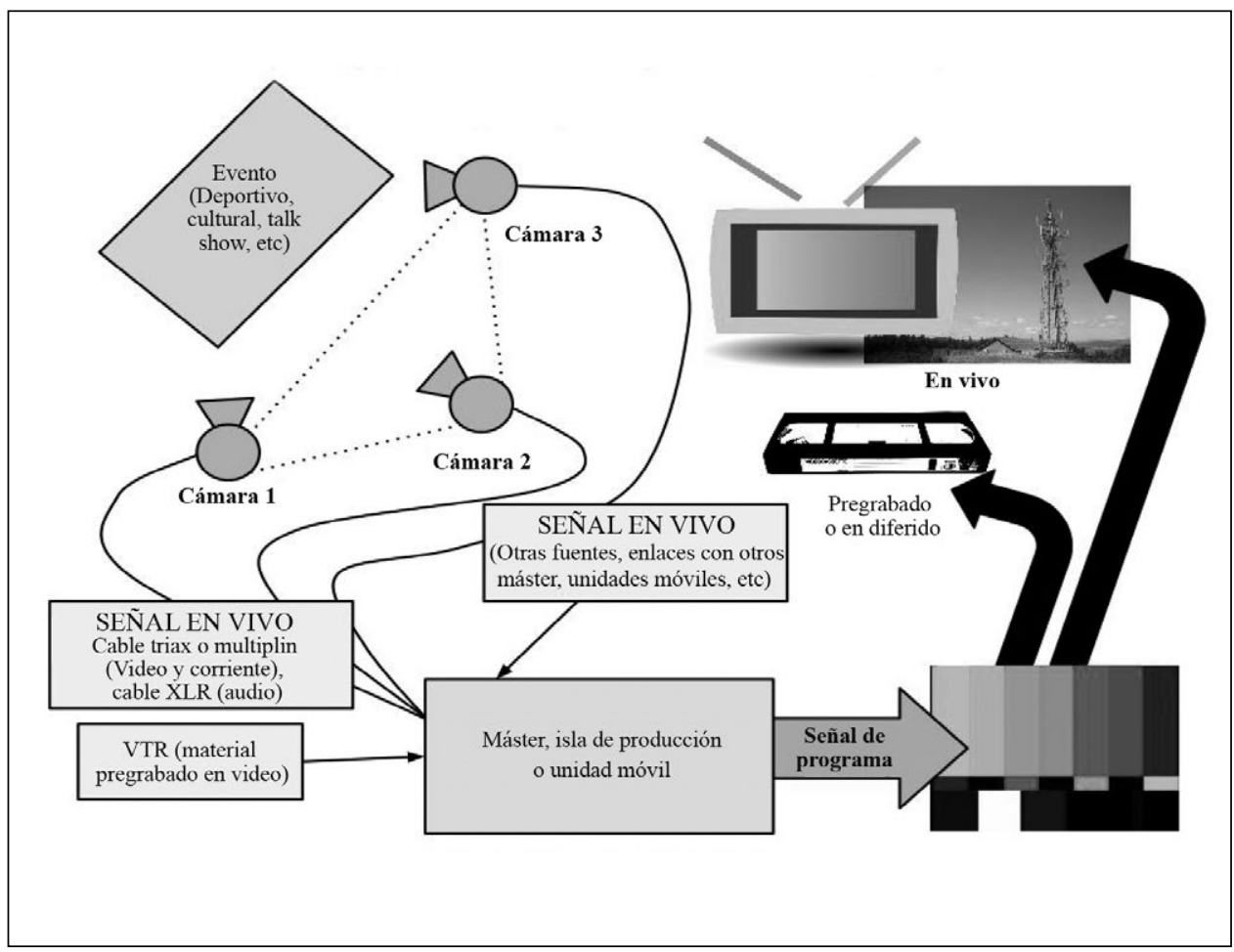

Fuente: Cardona (2012a). 
La discusión sobre qué tan plural o democrático es un medio como la televisión (o cualquier otra tecnología exclusiva) pasa por el uso de dicha tecnología y sus consecuencias sociales, y gira alrededor de si su uso es hegemónico o es abierto. La responsabilidad última sobre aciertos o fracasos, sobre arbitrariedades o inclusión recae en el poder central, como ente absoluto y administrador per se de la tecnología televisiva, que también podría ser la espacial, atómica u otra.

No se entiende por qué la discusión académica se centra sobre consecuencias e implicaciones sociales, saltándose (y aparentemente desdeñando) el entendimiento de la tecnología en sí misma, el de la minucia del proceso, que podría facilitar la democratización de la misma. Por supuesto, toda nueva tecnología requiere de expertos que la exploten para bien (o no) de un grupo social, pero ¿acaso el aumento del número de personas que entiendan una tecnología no haría que la misma se democratice? ¿Acaso levantando el velo de misterio de un proceso complejo como el de la televisión, y en consecuencia permitiendo que más gente se involucre en él, permitiría su transformación a un ritmo mayor?

¿Para qué seguir discutiendo si el Estado o la empresa privada usan hegemónicamente la televisión, pudiendo mejor comenzar a brindar herramientas para producir televisiones propias o nuevos medios propios? Tal vez el amor por tener "la sartén por el mango" (en el Estado, en la industria y en la academia) sea mayor que el deseo de compartir un descubrimiento para que cada quien lo use libremente.

\section{Descentralización de la televisión. Democratización y réplica de procesos}

En Colombia, a partir de 1984, se fundaron la mayoría de los canales regionales, descentralizando la televisión, fundada el 13 de junio de 1954 durante la dictadura de Gustavo Rojas Pinilla, que operó solamente en Bogotá por más de 30 años. Esto permitió que existieran expertos ingenieros y productores de contenido en diferentes regiones del país como Antioquia, Valle del Cauca, Santanderes, eje cafetero y costa atlántica (García Ángel, 2012).

A primera vista, desde la óptica de los mass media, la descentralización se estaba llevando a cabo, pero al final, desde el uso de la tecnología televisiva, no hubo mayor innovación dado que cada canal fue una réplica de los procesos industriales y de creación de contenido que ya se había hecho desde aquella televisora nacional de los años 50 .

Nadie cuestionó el montaje de un estudio o el flujo de trabajo de una produccción en vivo o pregrabada. Todos los canales regionales, desde Teleantioquia hasta Telepacifico, usaron estudios con cámaras cableadas por triax o multipin, máster de emisión, unidades móviles, ediciones A-B roll, U-matic, betacam, Avid, microondas... Lo mismo que la televisión de Bogotá, pero ahora en la región.

¿Cuál era la novedad, que era hecha de manera descentralizada? La innovación era en discursos y temas, en contenido, no en procesos. En términos del uso democrático 
de una tecnología, tanto en la televisión de Bogotá como en la de las regiones, se necesitó del mismo perfil de técnicos para la operación del mismo tipo de tecnología, cuyos montajes industriales podrían llegar a costar lo mismo, entonces ¿qué opciones tendría un televidente de llegar a hacer (sí, a producir) una televisión como la nacional o regional? ¿Qué alcances reales tendría esa descentralización o apertura, con tintes de democratización?

A finales de los años 90 se crearon canales locales en Bogotá (City T.V. y Canal Capital) y en otras ciudades se hizo lo mismo con más o menos recursos (con o sin respaldo de grandes grupos económicos, alcaldías o gobernaciones) pero al final seguía siendo una réplica de procesos de la televisión ya conocidos, usando formatos transversales como el DV, con coberturas dadas por redes de empresas de televisión por cable o emisión de ondas UHF para áreas pequeñas. Se producía así una "réplica de la réplica", incluso en las inversiones costosas, perfil de expertos y programación en parrilla unidireccionalizada.

En las universidades, la enseñanza de la televisión pasaba (para variar) por el replicar la infraestructura televisiva (la del estudio, las salas de edición, el cableado, etc) en productos que se difundían (o no) por redes cableadas o de UHF. Una infraestructura costosa para productos de estudiantes, con una difusión sin un impacto medible en un público objetivo (la población universitaria) y lo más preocupante: con una participación prejuiciosamente parcial de los estudiantes en los procesos de producción televisiva, porque la operación del flujo de trabajo pregrabado o en vivo (desde la televisión profesional en Bogotá hasta la hecha en las universidades) ha estado a cargo de "técnicos" y el contenido a cargo de estudiantes y profesionales en Comunicación Social, porque ha existido un entendimiento implícito de que la operación tecnológica la hace un personal formado o empírico, y la operación simbólica o ideológica, los profesionales.

Hay muchos de estos últimos que desdeñan la operación técnica (porque no la entienden o son incapaces). Sin embargo, los tiempos han cambiado y las curvas de aprendizaje de las complejas tecnologías televisivas (como la operación de un Avid o la manipulación de un Switcher Grass Valley para la producción en vivo) se han abaratado, facilitado y volcado al usuario final.

\section{Televisión web en el Externado (antecedentes y resultados)}

En la Universidad Externado, a principios del 2011, existían cabinas de radio y una sala de 20 computadores iMac que básicamente servían para producir contenido pregrabado, para radio o $\mathrm{TV}$, y los productos de los estudiantes no quedaban registrados como parte de una historia, ni tenían una difusión centralizada en un medio identificable.

Para muchos, YouTube era una alternativa de publicación y difusión del contenido hecho en clases. La producción de televisión en vivo fue la más afectada, en un contexto nacional que replica irreflexivamente una y otra vez la forma de hacer la televisión de antes, con roles replicados como el de los profesionales y los técnicos, etc. 
En el 2010 aparecen portales para consumir y producir televisión como Justin.tv, Ustream. tv y Livestream.com. Este último presentaba un desarrollo de software en la nube muy interesante, que replicaba aspectos clave de la producción en vivo, en una webapp llamada Livestream Studio, heredera del desarrollo de un proyecto llamado Mogulus (Neoteo, 2007). Ustream.tv y Justin.tv le dan la posibilidad a sus usuarios de consumir la televisión que otros usuarios producen o redireccionan (porque también hay contenido pirateado) y también le ofrece una webapp para hacer un unicasting o una transmisión de audio y video desde una fuente (webcam) hacia varios usuarios.

Livestream Studio permite enlazar varias fuentes de video y alternar una producción en vivo entre estas fuentes y video pregrabado previamente subido al servidor, que junto con un generador de caracteres y "pantallazos" (fotos JPEG) de fotos, permite hacer una producción en vivo completa, desde una aplicación en la nube, y fuentes remotas de video, que pueden estar cerca al Livestream Studio a pocos metros o incluso en otros países.

El primero de julio de 2010 el autor de este artículo, junto a un grupo de trabajo (Juan David Caro, Carlos Andrés Bedoya, Carolina Mora y Diana Ariza), hicieron la primera transmisión televisiva desde la web y para la web en Colombia, usando la aplicación web Livestream Studio, valiéndose de tres PC portátiles, tres cámaras mini DV (formato reconocido por la webapp) y conexión WiFi a Internet, para un recital del grupo de rock Los Superlitio, enmarcado en el evento "Piensa Joven", con previa inscripción de usuario y clave:

Figura 2: Afiche del recital transmitido desde la web.

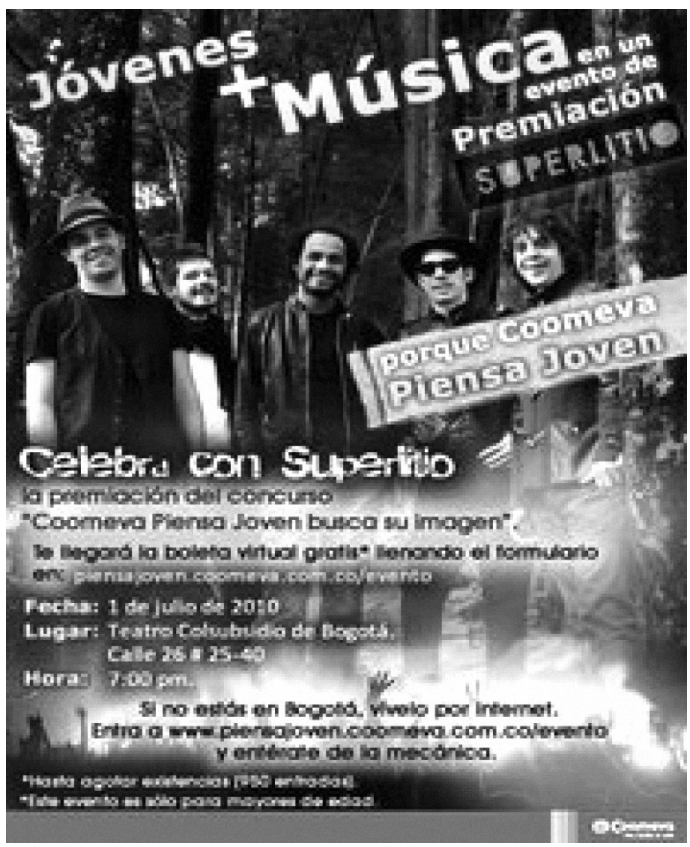

Fuente: Cardona (2010a). 
La primera opción para producir en vivo este evento era alquilar una unidad móvil digital con 15 técnicos para transmitir a varias cámaras conectadas a un switcher y luego emitir la señal de programa al portal dispuesto para el evento. Se optó por la solución de Livestream, dado que prescindíamos del uso de la tecnología tradicional de televisión, no solo en la captura del video sino en un detalle operativo aparentemente necesario, pero que en la televisión web hace la diferencia: el cableado.

En la televisión web no hay cables. Las cámaras pueden ser 1, 3 ó 20, y se originan desde computadores conectados a la misma cuenta de Livestream y de inmediato aparecen como fuentes de video en vivo disponibles en el Livestream Studio, sin importar a la distancia a la que estén de la PC que haga las veces de switcher, siempre y cuando estén conectadas a Internet y a la misma cuenta de Livestream.

Figura 3: Detrás de cámaras de la transmisión online del recital.

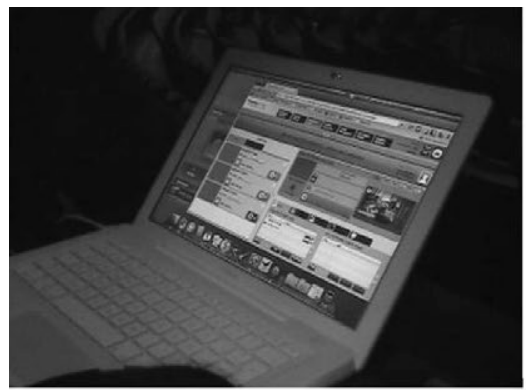

Concierto de Superlitio para "Coomeva Piensa Joven", Teatro Colsubsidio Bogotá. 1 de Julio de 2010.
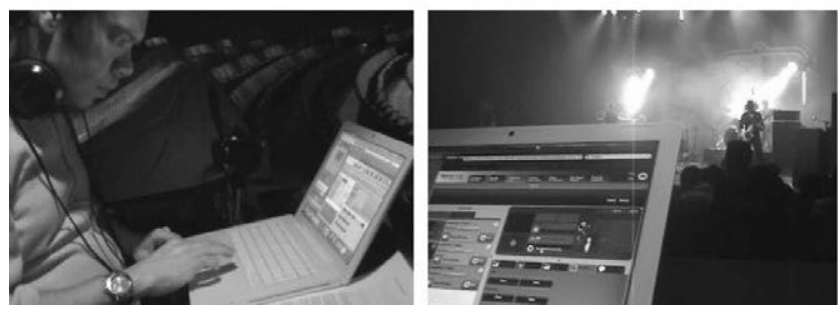

Fuente: Cardona (2010b).

En la Universidad Externado de Colombia se comenzaron a hacer emisiones de televisión web usando Livestream a partir de julio de 2011, abriendo el usuario "ExternadoTV", primero en una cuenta gratuita, que permitía conectar varias fuentes de cámara desde computadores conectados a la misma cuenta (se han hecho pruebas y hemos conectado hasta 20 cámaras de forma inalámbrica, algunas originando desde Argentina o Canadá) y con la posibilidad de enlazar fuentes de video móviles como iPhones, celulares Android o 
tabletas como el iPad o el Samsung Galaxy Tab 10.1, gracias a la aplicación QIK disponible tanto en iOS como en Android ICS (Ice Cream Sandwich), que desde www.qik.com se enlaza de forma simple y transparente con http://secure.livestream.com

Figura 4: Espacio de control o "máster de emisión” de ExternadoTV.

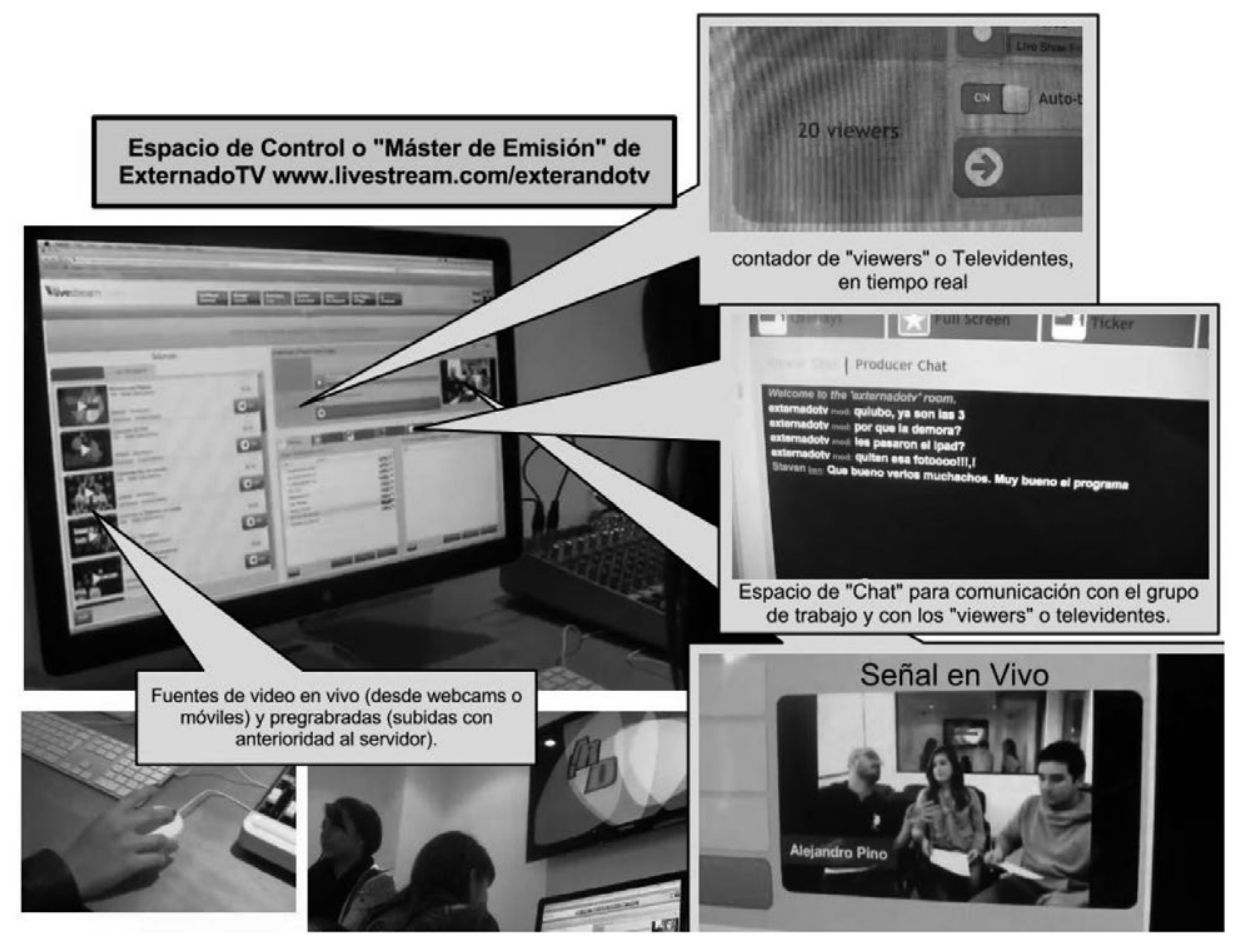

Fuente: Cardona (2012b).

Las pruebas se comenzaron a hacer a partir del 2011 con estudiantes de Comunicación Social-Periodismo, primero como ejercicio de clase, en donde se enseñaba en menos de dos sesiones a conectarse al sistema y a operarlo, ya fuera como fuente de video (cámara web o cámara DV conectada a un PC por puerto firewire) o como productor en vivo operando el Livestream Studio a modo de switcher y generador de caracteres.

Uno de los primeros programas creados, producidos, promovidos en redes sociales y operados en su totalidad por estudiantes fue "Par de Pelotas", un magazine deportivo de entregas semanales, que no estuvo circunscrito a ninguna materia del área audiovisual como trabajo académico. Los estudiantes lo desarrollaron como una actividad extracurricular. En este programa había una parte producida como notas periodísticas o cortos videos pregrabados, elaborados desde cualquier cámara (móvil, fotográfica o Full HD provistas por el Laboratorio de Medios de la Universidad) y editadas en cualquier software de edición no lineal (Adobe Premiere Pro, iMovie o Final Cut Pro, instalado en todos los terminales del Laboratorio de Medios del Externado). 
Asimismo, había otra parte producida en vivo, conectándose al usuario ExternadoTV de Livestream y gestionando la producción en vivo (o switcher de señales) desde www. livestream.com/studio y el enlace de cámaras desde www.livestream.com/webcaster o desde la aplicación móvil QIK.

Figura 5: Espacio de producción en vivo de "Par de Pelotas" de ExternadoTV.

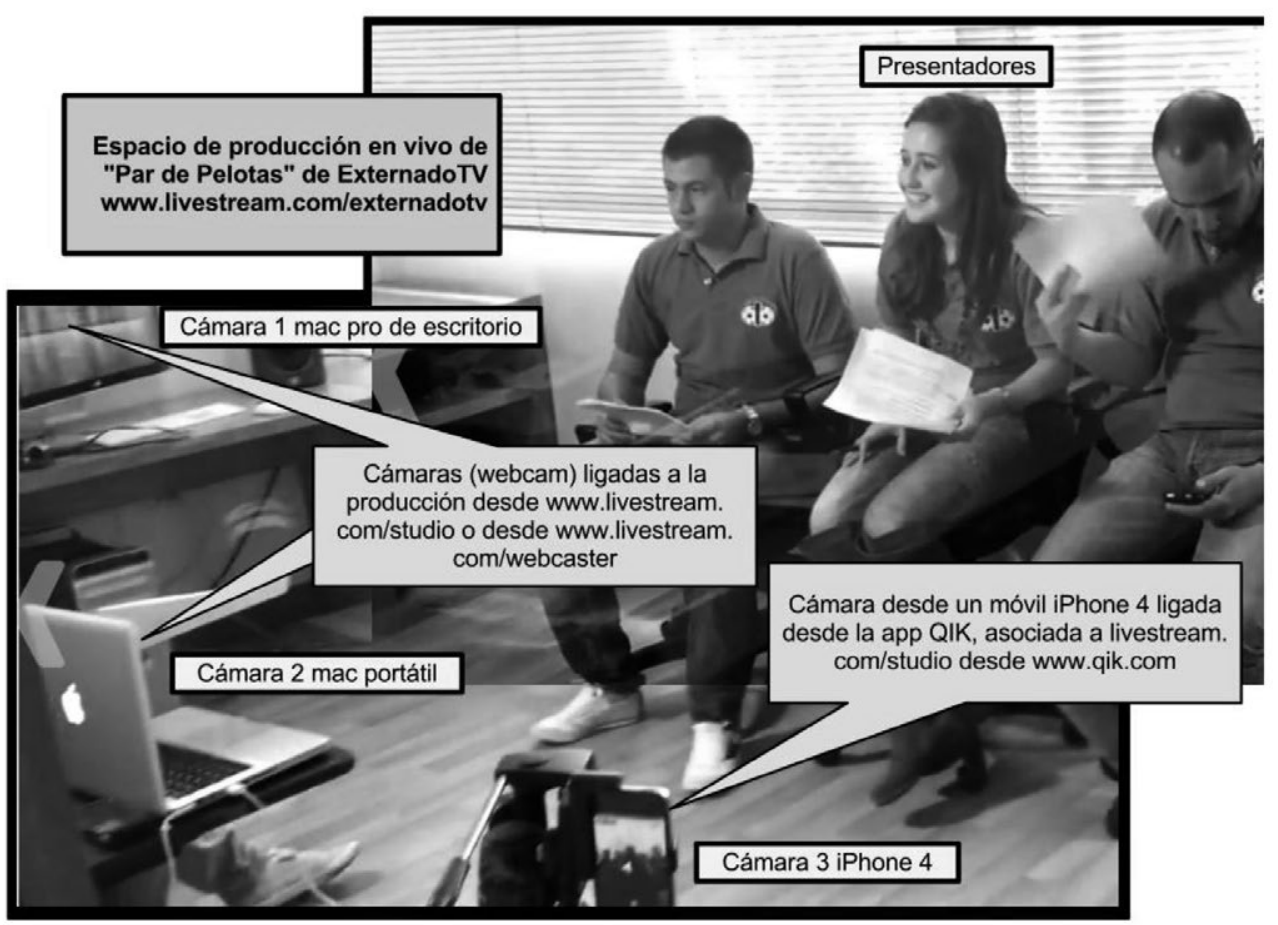

Fuente: Cardona (2012c).

La flexibilidad de uso de esta plataforma no solo radica en la operación desde la web, lo que permite usar casi cualquier dispositivo que se conecte a Internet, sea computador de escritorio, portátil o móvil. La otra ventaja es que los "roles", tanto de personas como de dispositivos (cámara o "switcher" en principio), se pueden intercambiar entre dispositivos y personas, porque al final tanto el enlace de cámaras como el control de señales o producción en vivo se hacen desde webapps y no dependen de dispositivo físico alguno, sino del acceso a un sitio web y al ingreso con usuario y clave.

Si el computador (que hace las veces de switcher o el que hace de cámara) deja de funcionar o se desconecta de la red, se abre el navegador de otro computador, tableta o móvil; se ingresa al usuario del canal con contraseña y se sigue trabajando sin cables desde cualquier lugar del mundo desde el que se ingrese, haciendo que el estudio de televisión o el máster de emisión sean cualquier lugar donde haya conexión a Internet. 


\section{Democracia directa en una televisión que nunca fue democrática}

La democracia llega de forma directa a un medio que fue designado por gobiernos elegidos por voto, es decir, el gobierno fue elegido para representar al pueblo, pero la televisión que ese gobierno creó no fue elegida por voto alguno, fue en muchos casos consecuencia del "ruido" entre la población y sus representantes, que ha derivado en corrupciones de todos los tamaños. Una televisión vertical y autoproclamada como representativa de la cultura de una nación. En el caso de la televisión privada, la única democratización ejercida es la de la libertad de creación de industria.

Las opciones son tantas en la televisión pública o privada durante el siglo XX que la discusión sobre representatividad de una cultura (sobre acceso a la tecnología televisiva y sobre interactividad) se han diluido entre la gran oferta de canales y sus raitings. Discusiones a las que no se les da curso ni siquiera con la llegada de la TDT, que por HD 1080i que sea su imagen, sigue teniendo el mismo espíritu unidireccional.

Con la televisión web, cualquier usuario (estudiante universitario, academia, industria o prosumidor) puede crear un canal de televisión con herramientas antes exclusivas de la televisión massmediática. Se conforman así televisiones representativas de los intereses de cada prosumidor, dirigidas a nichos de audiencia específicos, tal vez sin los dilemas de responsabilidad de la televisión del siglo XX, porque la tecnología (antes exclusiva y poderosa) hoy está al alcance de muchos.

Ahora bien, la televisión web que se plantea en este trabajo no es tan innovadora como se quisiera, es una simple migración de un proceso (antes analógico y luego digital) a un entorno remoto de computación en la nube, con la significativa diferencia de ser esta vez un proceso abierto y gratuito a quienes accedan a Internet. Apertura que la televisión del siglo XX y su exclusiva tecnología del video solamente tuvo a finales de los años 60 con la llegada de la Sony Portapack para deleite de los usuarios finales. Y hasta ahí llegó en el siglo XX, porque los sistemas de edición vinieron prácticamente con los PC a principios del siglo XXI y la producción en vivo a partir de Livestream. com más recientemente.

Un flujo de trabajo develado, un misterio descubierto y disponible. Por ser una migración, el flujo propuesto por Livestream emula en mucho la unidireccionalidad de la televisión del siglo XX. Cuando se miran los Hangouts de Google (con mucho del flujo de la televisión pero aun más flexible) y en donde usuarios, productores y audiencia se pueden confundir en variantes infinitas, ya se puede hablar de una "televisión conversacional". Una en la que la democracia directa, la del pueblo ejerciendo el poder, la de los prosumidores atendiendo y produciendo la TV que ven-consumen.

Ahí es cuando se evidencia la diferencia. Cuando se va más allá del reclamo a la televisión por su hegemonía o falta de pluralidad y se opta por hacer una televisión propia, sin procesos misteriosos. Una televisión para quien la quiera hacer. 


\section{Fuentes consultadas}

Cardona, F.

_(2012a). “Flujo de trabajo básico de Televisión”. Extraída el 12/VIII/2013 desde https:// docs.google.com/drawings/pub?id=1jIbXZlrnf5Xmrn4aoIQ9ebl4NDEABFzMo1brTNuR $\mathrm{CqA} \& \mathrm{w}=960 \& \mathrm{~h}=720$

_(2012b). "Espacio de control o 'Máster de Emisión' de ExternadoTV”. Extraída el 12/ VIII/2013 desde https://docs.google.com/drawings/pub?id=1afeMaByxNSVFCIODU6F9 HTGLQzzdKaXC4NN1cfQi5Rk\&w=960\&h=720

_(2012c). “Espaciode producción envivo de 'PardePelotas'deExternadoTV”.Extraídael 12/ VIII/2013 desde https://picasaweb.google.com/lh/photo/IjykuMfW9ZLRDqDpqr7JkNMT jNZETYmyPJy0liipFm0?feat=directlink

_(2012d). "Detrás de cámaras de 'Par de Pelotas"”. Extraída el 12/VIII/2013 desde https:// picasaweb.google.com/lh/photo/IjykuMfW9ZLRDqDpqr7JkNMTjNZETYmyPJy0liipFm 0 ?feat $=$ directlink

_(2010a). "Evento 'Coomeva Piensa Joven"”. Extraída el 12/VIII/2013 desde http://www. facebook.com/events/131544626874410/

_(2010b). "Detrás de cámaras concierto de Los Superlitio para el evento 'Coomeva Piensa Joven"”. Extraída el 12/VIII/2013 desde https://docs.google.com/drawings/pub?id =1QZQzXvm14EvnDaubcWbq3-7LgZ0ipqebvT86sCodLrU\&w=960\&h=720

Carracedo, J.; Pérez Belleboni, E. y Carracedo, J. (2010). "Hacia el voto telemático: Exigencias sociopolíticas y viabilidad técnica". En Carracedo, J. (coord.). Democracia digital, participación y voto electrónico. Madrid: Ediciones del Centro de Estudios Políticos y Sociales.

Cronicon.net (2011, julio 31). "Un Manto de Corrupción cubre el cuestionado gobierno de Álvaro Uribe Vélez”. Extraída el 12/VIII/2013 desde http://www.cronicon.net/paginas/ edicanter/Ediciones60/nota13.htm

Democracia Directa Digital (2011, abril 27). "La nueva democracia islandesa". Extraída el 12/VIII/2013 desde http://www.d-3.info/democraciadirecta/2011/04/27/la-nueva-democraciaislandesa/

Democracia Líquida (2012). "Qué es la Democracia Líquida”. Extraída el 12/VIII/2013 desde http://www.democracialiquida.org/

EducarChile (2008, octubre 15). "Historia de la democracia. Cómo vivían la democracia los griegos". Extraída el 12/VIII/2013 desde http://www.educarchile.cl/Portal.Base/Web/ VerContenido.aspx?ID=188867

El Tiempo, diario (2012). "Los 10 momentos claves en su paso por la Alcaldía de Bogotá". Extraída el 12/VIII/2013 desde http://www.eltiempo.com/Multimedia/infografia/ samuelmoreno/ 
Gallardo, J. y Belleboni, E. (2012). "Voto electrónico, voto telemático y voto por Internet: requisitos socialmente demandables y técnicamente viables". Extraída el 12/VIII/2013 desde http://vototelematico.diatel.upm.es/articulos/Voto_electronico_Salamanca.pdf

García Ángel, A. (2012). "Televisión en Colombia: Surgimiento de los canales regionales". Extraída el 12/VIII/2013 desde http://www.politecnicojic.edu.co/luciernaga7pdf/3 canales_regionales.pdf

Heilbroner, R. (1967). “¿Son las máquinas el motor de la historia?” Revista Technology and Culture, núm. 4, pp. 335-345.

Merriam-Webster Dictionary (2013). "Democracy”. Extraída el 12/VIII/2013 desde http:// www.merriam-webster.com/dictionary/democracy

Neoteo (2007). "Mogulus: Tu propio canal de Televisión”. Extraída el 12/VIII/2013 desde http://www.neoteo.com/mogulus-tu-propio-canal-de-television/

Pérez, M. (2007). "Historia de la Televisión”. Extraída el 23/IX/2013 desde http://www. asociacionplaza delcastillo.org/Textosweb/HistoriadelaTelevision.PDF

Winner, L. (1985). “¿Tienen política los artefactos?”. En Mackenzie, D. y otros (eds.). The Social Shaping of Technology. Philadelphia: Open University Press. 